2ad dictionary of all the principal Malayo-Polynesian dialects, and am trying to reduce the whole to a uniform system of ortho. graphy.

Samoa, Jan. 3

\section{The Visible Horizon}

A POINT of some scientific interest has just been argued in the High Court of Justice. It was contended by the SolicitorGen ral that the three miles' limit of territorial waters was of motem origin, and by Sir R. Phillimore that it was due to that being the distance a cannon ball would reach from the shore. There can, however, be no doubt that the limit was recognised long before the invention of gunpowder.

Three miles is the distance of the offing or visible horizon to a person six feet in height standing on the shore. It is natural to suppose that the early maritime peoples of Europe would lay supo for as the eye could reach. This distance they would find hy experience was just three miles, and it can be proved mathematically to be correct. Measured by this standard -a tall man, usually taken as six feet high-the distance is invariable for all time, places, and peoples; measured by a cannon ball, it is constantly varying, and now ought to be five miles rather than three. The fact that the distance depends on both ocular and mathematical demonstration, and is not subject to improvement in gunnery, is the best explanation of its origin and application.

Dulwich, May 8

B. G. JENKINS

\section{Lunar Maps}

LOHRMAN's complete map, three feet in diameter, four sections of which were published in 1824 , has been recently engraved by J. A. Barth, of Leipzig, under the supervision of Dr. Schmidt, director of the Athens Observatory, who has contributed a descriptive letterpress.

Schmidt's own map of six Frenclz feet diameter, will be issued before the end of the present year, from the atelier of the Royal Prussian Staff, the Prussian Government having, with great credit to itself, purchased that incomparable work. It is the result of thirty-four years' labour, and contains about 34,000 craters and an equal number of hills, besides over 350 rills and other objects. The difficulty of noting and correctly mapping this amazing number of lunar formations will be understood by anyone at all acquainted with the subject; and it will be seen that Dr. Schmidt has completed an achievement not surpassed in scientific capability and perseverance. A written text wi!l accompany the map.

It were to be wished that our own countryman, Mir. Birt, could look forward to a similar recognition of his services. His great lunar map, of which we have heard nothing for some time, is on a plan quite different from Schmidt's, to which it would be found, if completed, an invaluable accompaniment by observers of the lunar surface; and it will speak but little for the scientific taste of our country if Mr. Birt's work is allowed finally to collapse for want of appreciation and encouragement. Millbrook, Tuxm, Ireland

J. BIRMINGHAM

\section{OUR ASTRONOWICAL CULUMN}

THE STdR-LALANDE 27095 (BOOTES).-Olbers, writing to Bode in July, I804, respecting his observations of the comet of that year, remarks of Lalande 27095 , near the place of which star the comet was situated on March 22 : "Ist nicht inehr am Himmel zu finden." It was observed by Lalande as a seventh magnitude, I795, May 25 ("Histoire Céleste," p. 164), centre wire at I4h. 42m. Ios.

The star was observed by Bessel, I828, May 24, as a gth magnitude, and is No. 976 of Hour xiv, in Weis: e's second catalogue. In the "Durchmusterung" it is 9"0. There is evidently reason for supposing the star to be variable.

It follows the sixth-magnitude-star B.A.C. 4906, 19s., and is $6^{\prime} 37^{\prime \prime}$ north of it, the position for the beginning of the present year being R.A. 14h. $45 \mathrm{~m}$. $56 \mathrm{~s}$., N.P.D. $52^{\circ} 6^{\prime \prime} 5$.

THE FrRST COMET of 1743.- -Notwithstanding the very marked deviation of the orbit of this comet from a parabola, it does not appear that any attempt has yet been made to determine, directly from the observations, the true form of the orbit, or at any rate to work out elements which will satisfy the observations within their probable limits of error. It is true that these observations, with one or two exceptions, are by no means exact, and Olbers, who examined the question in 1823 , was of opinion that, from their general uncertainty, an investigation into the nature of the conic section described was hardly worth the trouble it would involve. Notwithstanding this expression of opinion from so high an authority, it may be remarked that there are a sufficient number of observations in our possession which cannot fairly be supposed liable to serious errors to justify an attempt to deduce more satisfactory elements than those hitherto calculated.

The comet appears to have been first observed by Grischow or Grisso, at Berlin, on February Io, and his observation on the evening of that day was considered by Olbers to be the most certain of any he made upon this comet, and not liable to a greater error than $2^{\prime}$ or $3^{\prime}$. On February I4, 15, I6 and 19, Grischow, observing apparently with Margareta Kirch, also gives particulars from which probably fair positions might be deduced. And we have an observation by Father Frantz, of Vienna, on February 21, given in proper form in the "Philosophical Transactions" of the Royal Society. Also a good observation by Maraldi at Paris on February I3, and one by Cassini on February 17, which last, however, is open to some doubi, not only for a reason pointed out by Olbers, but from an error as to the comparison star. Zanotti's observations at Bologna, form the longest series, and extend from February 12 to 28 , but they are only publishęd (in Mémoires de l'Academie, I743) in longitude and latitude to minutes of arc, without further detail, and were not given by Zanotti as having any pretensions to accuracy. The parabolic orbit with which Olbers was content to discontinue his computations was the following :-

Perihelion Passage, I743, Jan. io, at 20h, 29m. 37 . Paris M.T.

$\begin{array}{ccccccc}\text { Longitude of perihelion ... } & \ldots & \ldots & 92 & 57 & 51 \\ \text { In } & \ldots & \text { ascending node } & \ldots & 67 & 31 & 57 \\ \text { Inclination to ecliptic } & \ldots & \ldots & \ldots & 2 & 16 & \text { I6 }\end{array}$

Perihelion distance... distance $=$ I)

These elements agree well, according to Olbers, with the positions observed on $\mathrm{Feb}$. Io and 28 , and with the longitudes on Feb. 13 and 2I, but the latitudes on these days differ by $14^{\prime}$ and $10^{\prime}$ respectively, which is precisely the lsind of discordance, which we might expect to find, if the true orbit of the comet were an ellipse of short period. It will be remembered that Clausen considered this come identical with that of November I819, detected by Blanpain at Marseilles, with a period of 6.73 years before $175^{\circ}$ and 5.60 years after 1817 , and that at the suggestion of Olbers the perturbations were calculated at the Collegio Romano to the year 1836 , when the comet had been expected to reappear. The orbit of short period which appears in catalogues with Clausen's name, was calculated from Zanotti's observations of Feb. I2, 20, and 28 , with a pre-supposition as to the length of the major-axis. As already remarked, no attempt, so far as we know, has yet been made to deduce elements direct from the observations, which shall represent them with smaller errors than the parabolic orbits of Lacaille, Olbers, and Struyck.

Grischow records that on the evening of Feb. II, I743, the apparent diameter of the comet was $18^{\prime}$, that it appeared like a greyish-white cloud, but with close attention, "ein kleines helles Pünctlein in der Mitte gewahr." We find by calculation that the comet at this time was distant from the earth only o'O5 1 of the earth's mean distance from the sun, and are reminded that such an object would have afforded an opportunity of the kind to which Mr. Marth has lately adverted, for a determination of the amount of solar parallax. A similar opportunity 